OPEN ACCESS

Edited by:

Andrei S. Chagin,

Karolinska Institutet (KI), Sweden

Reviewed by:

Raul R. Gainetdinov,

Saint Petersburg State University,

Russia

Johannes F. W. Greiner,

Bielefeld University, Germany

*Correspondence:

Vyacheslav Dyachuk

slavad83@gmail.com

Specialty section:

This article was submitted to

Stem Cell Research,

a section of the journal

Frontiers in Cell and Developmental

Biology

Received: 26 April 2020

Accepted: 31 July 2020

Published: 18 August 2020

Citation:

Milichko V and Dyachuk V (2020)

Novel Glial Cell Functions: Extensive Potency, Stem Cell-Like Properties, and Participation in Regeneration

and Transdifferentiation.

Front. Cell Dev. Biol. 8:809.

doi: 10.3389/fcell.2020.00809

\section{Novel Glial Cell Functions: Extensive Potency, Stem Cell-Like Properties, and Participation in Regeneration and Transdifferentiation}

\author{
Valentin Milichko ${ }^{1}$ and Vyacheslav Dyachuk ${ }^{1,2 *}$ \\ ${ }^{1}$ Department of Nanophotonics and Metamaterials, ITMO University, St. Petersburg, Russia, ${ }^{2}$ National Scientific Center \\ of Marine Biology, Far Eastern Branch, Russian Academy of Sciences, Vladivostok, Russia
}

Glial cells are the most abundant cells in both the peripheral and central nervous systems. During the past decade, a subpopulation of immature peripheral glial cells, namely, embryonic Schwann cell-precursors, have been found to perform important functions related to development. These cells have properties resembling those of the neural crest and, depending on their location in the body, can transform into several different cell types in peripheral tissues, including autonomic neurons. This review describes the multipotent properties of Schwann cell-precursors and their importance, together with innervation, during early development. The heterogeneity of Schwann cells, as revealed using single-cell transcriptomics, raises a question on whether some glial cells in the adult peripheral nervous system retain their stem cell-like properties. We also discuss how a deeper insight into the biology of both embryonic and adult Schwann cells might lead to an effective treatment of the damage of both neural and non-neural tissues, including the damage caused by neurodegenerative diseases. Furthermore, understanding the potential involvement of Schwann cells in the regulation of tumor development may reveal novel targets for cancer treatment.

Keywords: Schwann cell precursors, peripheral glial cells, heterogeneity, plasticity and multipotency, reprogramming, neurological diseases, carcinogenesis

\section{INTRODUCTION}

Peripheral glial cells encompass a wide variety of cell types, including myelinating Schwann cells, non-myelinating Schwann (Remak) cells (Jessen and Mirsky, 2010), glia of the enteric nervous system (Ochoa-Cortes et al., 2016), satellite glial cells of peripheral ganglia, and perisynaptic Schwann cells (PSCs) located in neuromuscular junctions (Alvarez-Suarez et al., 2020). In addition, boundary cap cells give rise to terminal glia associated with dermal nerve endings (Zujovic et al., 2011; Gresset et al., 2015). Moreover, researchers have described other small subpopulations of glial cells, such as olfactory ensheathing cells that envelop bundles of axons in the olfactory bulb ( $\mathrm{Su}$ and He, 2010) and specialized subtypes of glial cells in sensory organs (Ruffini endings, Krause end bulbs, and Meissner's and Pacinian corpuscles) (Byers, 1985; Maeda et al., 1999; Kastriti and Adameyko, 2017). 
Classically, peripheral glial cells have been viewed as multifunctional, nourishing, supporting and protecting neurons, myelinating axons, regulating synaptic connectivity and sensory function, and participating in the maintenance and regeneration of the peripheral nervous system (Barres, 2008). In recent decades, researchers have discovered that glial cells also play additional novel and unexpected roles, both during development and in adult animals (Adameyko et al., 2009; Dyachuk et al., 2014; Kaukua et al., 2014; Abdo et al., 2019; Xie et al., 2019), including participation in diseases (diabetes, tunnel syndrome, nerve paralysis, Guillain-Barre syndrome) (Gonçalves et al., 2018).

\section{Involvement of Schwann Cell Populations in Development}

Traditionally, terminally differentiated peripheral glial cells (or Schwann) cells (SCs) have been thought to derive directly from multipotent neural crest cells (NCCs), which appear for only a short time during early mammalian development, and then give rise to a variety of other cell types (Le Douarin and Kalcheim, 1999). However, this concept has been challenged by several recent studies involving lineage tracing that have revealed the existence of Schwann cell precursors (SCPs) with transcriptional profiles similar to those of SCs and NCCs (Adameyko et al., 2009; Kastriti and Adameyko, 2017). These SCPs can differentiate into an extraordinary variety of cell types, including immature Schwann cells, which subsequently differentiate into the myelinating and non-myelinating Schwann cells, associated with peripheral nerves. Recent data, showed that embryonic Schwann cells are able to differentiate into endoneurial fibroblasts (Joseph, 2004), pigment cells (Adameyko et al., 2009), parasympathetic neurons (Dyachuk et al., 2014), mesenchymal dental cells (Kaukua et al., 2014), enteric neurons (Espinosa-Medina et al., 2017), chromaffin cells of the adrenal gland (Furlan et al., 2017), cells of the Zuckerkandl organ (Kastriti et al., 2019), chondrocytes, and osteocytes (Xie et al., 2019; Figure 1).

Are Schwann cell precursors needed, in association with early development, when a population of NCCs, that appears earlier, can produce a wide range of cell types? One fundamental difference between these two types of cells is that NCCs migrate along a concentration gradient of growth factors released by neighboring tissues during a specific $24 \mathrm{~h}$ period, whereas SCPs are continuously associated with rapidly growing embryonic nerves, migrating together with them to quickly reach, even distant, regions of the body. The relatively large size of mouse and chicken embryos requires a rapid and appropriately timed delivery of undifferentiated cells to various locations where they give rise to several specialized types of cells, a function that SCPs are capable of performing.

In this context, the mechanism(s) by which SCPs attach and detach from growing nerves and the temporal and spatial regulation of these mechanism(s) remain(s) unclear. It is known that the signals released by axons, as well as the actual physical interaction of axons with SCPs, are involved in the survival and differentiation of SCPs (Birchmeier and Nave, 2008), influencing their subsequent differentiation into specialized cell types (Dyachuk et al., 2014). The signaling pathway involving the neuregulin-ErbB heteromeric receptor plays crucial roles in both SCP migration and in the survival of glial cells (Birchmeier, 2009). For example, in teleost fish, the association of SCPs with nerves and their glial commitment are controlled by this pathway (Garratt et al., 2000; Honjo et al., 2008). Moreover, similar mechanisms are active in the mammalian peripheral nervous system (Britsch et al., 1998; Jessen and Mirsky, 2005; Dyachuk et al., 2014), as demonstrated by the observation that, in mice in which ErbB2 has been genetically ablated, no SCPs are associated with the developing nerves, ultimately resulting in the widespread death of both motor and sensory neurons. Sox10, ErbB3, or Nrg1 genes are responsible for the survival of SCPs, and the inactivation of these genes led to the degeneration of motor and sensory neurons (Riethmacher et al., 1997; Wolpowitz et al., 2000; Britsch et al., 2001). Genetic ablation of peripheral nerves in mouse embryos or the pharmacological impairment in zebrafish larvae depleted SCPs nerve-associated SCPs, thereby preventing the appearance of neurons of the PNS and of melanophore stem cells (Dooley et al., 2013).

Comparative single-cell transcriptomic analysis of NCCs and SCPs has revealed that these two embryonic cell populations express many common transcription factors (TF) (Kastriti and Adameyko, 2017; Soldatov et al., 2019). As shown before, during early differentiation, SCPs programming is downregulated, while neuronal, neuroendocrine (e.g., chromaffin cells), or mesenchymal (odontoblasts, chondrocytes, and osteocytes) traits are upregulated (Dyachuk et al., 2014; Kaukua et al., 2014; Furlan et al., 2017; Xie et al., 2019). What determines the specialization direction in which a SCP will develop remains unclear. Are the different nerve and body locations of SCPs involved in their type of specialization? Perhaps the specific signals released by cells in the innervated target organs help to determine the fate of SCPs. Appropriately designed experiments are required to answer these fascinating questions.

\section{Natural (Adaptive) Reprogramming of Schwann Cells}

Differentiated definitive somatic cells can be reprogrammed by enhancing the levels of the Yamanaka factors (Takahashi and Yamanaka, 2006). At the same time, specialized cells in certain adult mammalian tissues can be naturally reprogrammed in response to an injury (Merrell and Stanger, 2016). The most well-known example of such an adaptive reprogramming is the transformation of myelin cells into cells with a non-myelinating Schwann cell phenotype, following certain types of injuries of the nervous system. Schwann cells have a unique capacity to promote the recovery of axons. After detaching from their axons, these cells release neurotrophic factors that improve the axonal survival. Moreover, by radically changing the local signaling environment, they participate in the autophagy of myelin and in the expression of cytokines, being also able to attract macrophages for myelin clearance. Finally, SCs proliferate to replace the lost cells and differentiate to elongate, branch, and form regeneration tracks (Bungner bands) (Jessen et al., 2015; Figure 2). The molecular profiling of glia cells following 


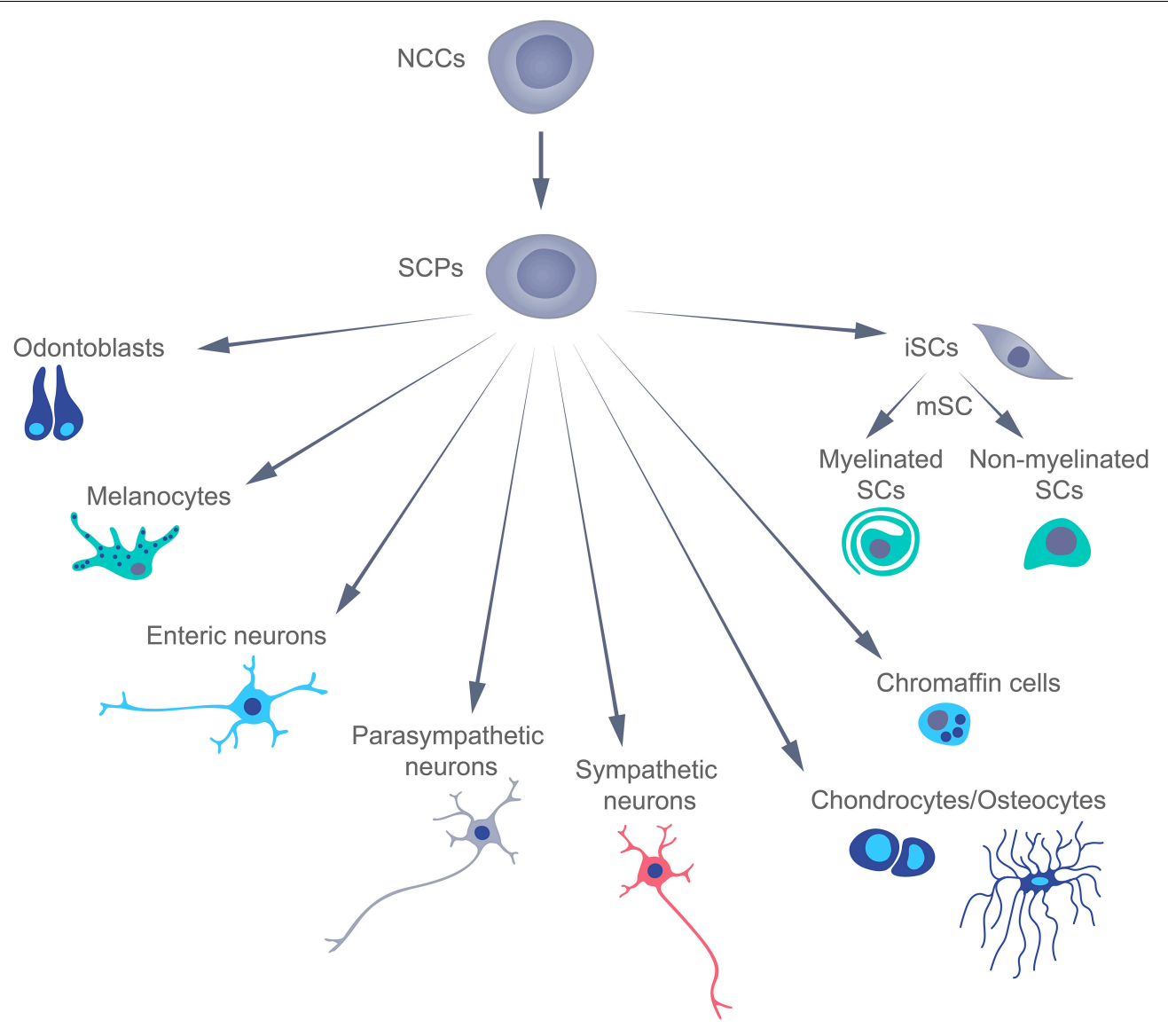

FIGURE 1 | The multipotency of Schwann cell precursors during early mammalian development.

injury is now receiving considerable attention, in order to determine their status.

Transcriptional profiling indicates that, following injury, Schwann cells acquire some properties of immature SCs, with concomitant repression of genes encoding proteins involved in the production of myelin (BrosiusLutz and Barres, 2014; Jessen and Mirsky, 2016). It should be emphasized that this transformation of mature Schwann cells into reparative Schwann cells is not actually dedifferentiation, although this process has been designated as such, previously. Indeed, this process involves the de novo expression of genes (Shh and Olig1) that are never expressed by embryonic Schwann cells, and whose expression is a unique aspect of the response to injury (Arthur-Farraj et al., 2012; Lin et al., 2015). At the same time, the transcription factor SOX2, a marker of developing SCPs, becomes upregulated as part of this reprogramming (Johnston et al., 2016).

The key molecular molecules that participate in this reprogramming of SCs include both certain transcription factors (e.g., c-JUN, SOX2) and signaling pathways (ERK, $\mathrm{NOTCH}$ ). Moreover, the molecular characterization of bridge and distal stumps of transected nerves indicates that, during reprogramming, SCs acquire mesenchymal traits, i.e., this process is somewhat similar to an epithelial-to-mesenchymal transition (EMT) (Arthur-Farraj et al., 2017; Clements et al., 2017).
Epigenomic changes in Schwann cells play an important role in differentiation and in their myelination (Woodhoo et al., 2009; Arthur-Farraj et al., 2012; Napoli et al., 2012; Jessen et al., 2015; Ma et al., 2016). However, epigenomic reprogramming of SCs in response to injury has not yet been characterized in detail. For example, HDAC-mediated deacetylation of promyelinating transcription factor NF- $\kappa \mathrm{B}$ is essential for the differentiation and myelination of SCs in vitro (Nickols et al., 2003; Chen et al., 2011). In contrast, the activation of NF- $\mathrm{BB}$ is not required for myelination of SCs in vivo (Morton et al., 2013). This discrepancy may indicate that the myelination of SCs during development, and following injury, is regulated by different transcriptional programs. Although NF- $\kappa \mathrm{B}$ appears to regulate EMT genes, as shown for several human cancers (Pires et al., 2017), the underlying mechanism of the action NF- $\mathrm{KB}$ in glia development and myelination remains unknown.

Moreover, the findings concerning the levels of expression of TFs by SCs following injury are also in disagreement, sometimes. For example, some researchers have observed no changes in the levels of SC markers (Jessen et al., 2015), while others have found a decreased expression of transcription factors (Clements et al., 2017). Such discrepancies raise questions concerning the true nature of SCs during reprogramming. On the one hand, 


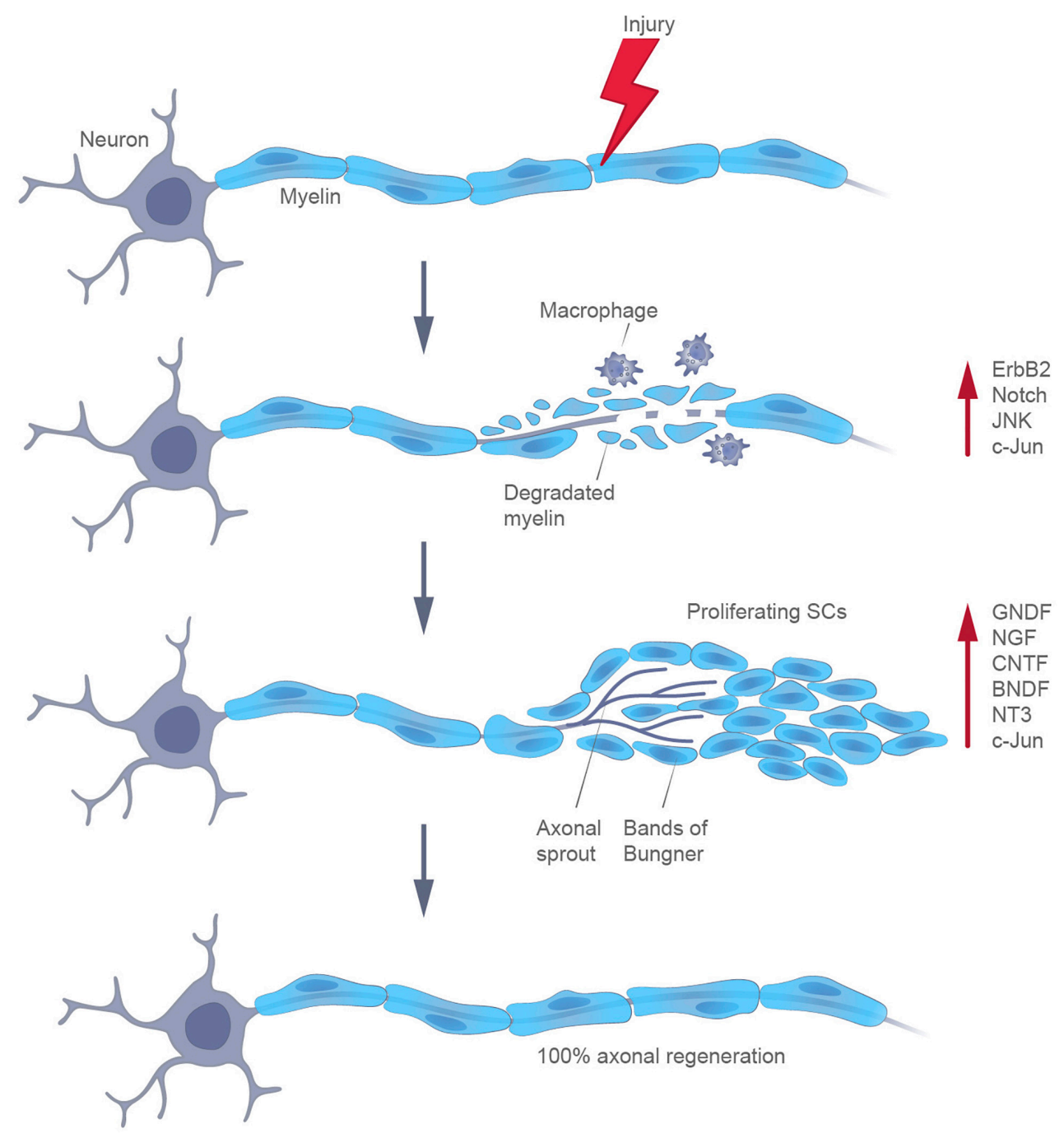

FIGURE 2 | Participation of Schwann cells in the regeneration of peripheral axons, following injury.

an upregulation through a transcriptional program orchestrated by c-JUN re-programs cells to become "repair" glial cells, with their own specific molecular signature (Arthur-Farraj et al., 2012); while on the other hand, the similarity of expression of transcription factors that is characteristic of EMT and of reprogrammed SCs after injury indicates their relationship to neural crest stem cells and/or to their own progenitors, SCPs or immature SCs.

Of course, there is also the possibility that there are subpopulations of SCs that have been reprogrammed in different ways (mesenchymal, immature glial, and neural crest) at different sites of injury (Figure 3A).

Another function performed by SCs in adults is the participation in the regeneration of the tips of the digits. After injury of the ends of fingers or toes, the transcription factor SOX2 is upregulated in the SCs associated with the damaged nerves. These cells, then, detach from their axons and migrate into the regenerating region, where they secrete paracrine growth factors that induce the proliferation of the resident mesenchymal precursors (Johnston et al., 2016). Accordingly, genetic ablation of Sox2 in SCs and denervation impairs the regeneration of nails and bones in mice and this regeneration can be rescued by transplantation of neonatal SCs (expressing SOX2) cultured in vitro into the injured digits (Le et al., 2005; Taranova et al., 2006; Johnston et al., 2016).

The skin is often used as a model system for research on regeneration, containing many different types of cells, including stem and progenitor cells. The skin of mice and humans is permeated by dense axons of a small diameter that are often severely damaged, in association with injuries of various kinds. In general, the recovery of thin axons in the skin resembles the analogous processes that occur in other parts of the PNS.

In injured skin, SCs detach from the nerves and undergo reprogramming and, later, division, in order to restore lost cells (Johnston et al., 2013). SCs expressing the glial markers SOX2 and S100b actively migrate into the healing dermis to aid in 

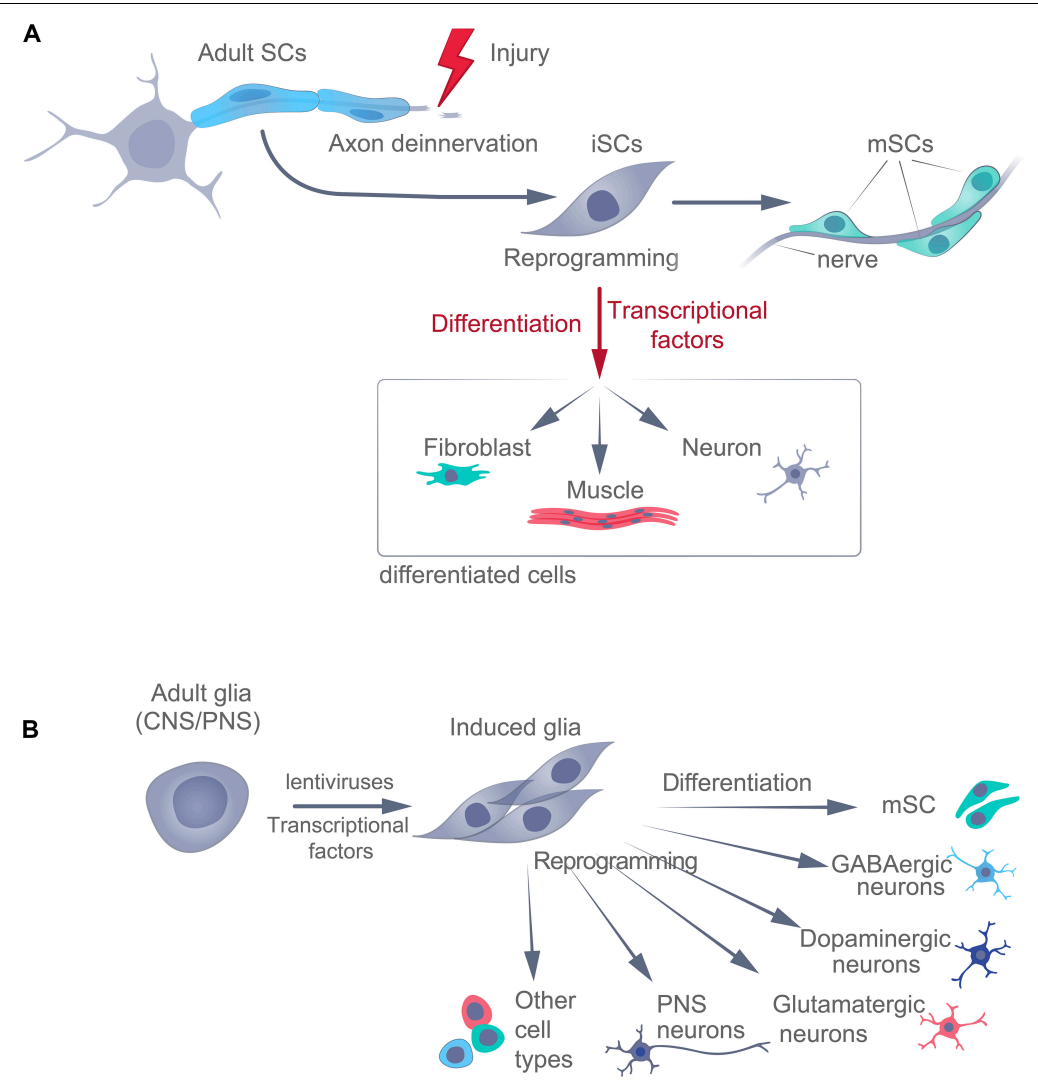

FIGURE 3 | Naturally occurring (adaptive) (A) and experimental (B) reprogramming of adult glial cells, following injury. SCs, Schwann cells; iSC, immature Schwann cells; mSC, mature Schwann cells.

its repair, probably by forcing mesenchymal cells to proliferate (Johnston et al., 2013). DTA-dependent ablation of SOX2 ${ }^{+}$-glial cells reduces the proliferation of dermal and epidermal cells, thereby impairing wound healing (Johnston et al., 2016).

Interestingly, SOX2/S100b/P75 ${ }^{+}$glial cells, which may participate in dermal maintenance and wound-healing, attach to axons surrounding the hair follicles (Hunt et al., 2008; Biernaskie et al., 2009), but this still remains unclear. Peripheral glial cells activated in response to injury can promote wound healing in the skin of adult mice. Such repairing SCs detach from the injured nerves and move into the granulation tissue, where they are reprogrammed into invasive mesenchymal-like cells and drive peripheral nerve regeneration (Clements et al., 2017; Parfejevs et al., 2018).

These examples of the participation of Schwann cells, together with axons, in the regeneration of nerves and target tissues, make these cells attractive for regenerative therapies. However, a more in-depth molecular understanding of these processes is required before clinical application can be considered.

Moreover, in zebrafish, Müller glia in the retina can differentiate into neurons in response to lesions (Raymond et al., 2006) through a process dependent on TF ASCL1 (Ramachandran et al., 2010). Thus, in addition to helping restore small damaged axons, forcing the proliferation of mesenchymal cells, and participating in dermal maintenance and wound healing, as well as in the regeneration of nails and bones, glial cells may be involved in adult neurogenesis. Reprogrammed iSCs may even be sources of other types of cells in adult vertebrates, in response to damage (Figure $\mathbf{3 A}$ ).

\section{Experimental Reprogramming of Schwann Cells}

Terminally differentiated somatic cells can be induced to become pluripotent (dedifferentiation) or switch to a different specialized phenotype (transdifferentiation). Experimental differentiation of SCs into neurons in adults is complicated and time-consuming and has not yet been standardized. Transdifferentiation involves reprogramming the cell, which directly switches the cellular phenotype to that of another somatic cell type (Figure 3B), e.g., the conversion of glial cells into neurons. This can be achieved experimentally, both in vitro and in vivo, using many different approaches - either indirectly (via iPSCs using TF or via iNPCs using $\mathrm{TF}^{+}$differentiation factors) or directly (using pro-neuronal $\mathrm{TF}^{+}$differentiation and maturation factors or chemicals), each with its own advantages and disadvantages. For example, in cell culture, a chemical cocktail containing inhibitors of HDACs, GSK-3 kinases, and TGF- $\beta$-mediated pathways, in combination with hypoxia, can reprogram fibroblasts into neuroprogenitor cells (Cheng et al., 2014). In addition, fibroblasts can be reprogrammed directly into neurons using small molecules 
alone (Li et al., 2014; Hu et al., 2015). In connection with these promising procedures for the transformation of somatic cells, the cells obtained still need to be genetically and functionally characterized, and these experimental protocols require standardization.

To reprogram cells using regulatory factors, bacterial or viral vectors are introduced into cells to cause an overexpression of key transcription factors, and thereby, initiate transdifferentiation (Patel and Yang, 2010; Grath and Dai, 2019); CRISPR/Cas9 gene editing can also employed to alter the pattern of gene expression directly (Rubio et al., 2016); or drugs that target transcription factors can be used to give rise to epigenetic remodeling (e.g., for transdifferentiation of human fibroblasts into endothelial cells, cardiac cells into skeletal myocytes, and mesenchymal stem cells into cardiomyocytes) (Naeem et al., 2013; Kaur et al., 2014; Sayed et al., 2015). Of these three approaches, the direct reprogramming of neuronal cells by introduction of lentiviral vectors that results in an overexpression of specific transcription factors is the most popular and effective, at present. Examples of cells that have been transdifferentiated into neurons, to date, include glia (Heins et al., 2002), mouse and human fibroblasts (Vierbuchen et al., 2010; Yoo et al., 2011; Adler et al., 2012), and fibroblasts and astrocytes (Addis et al., 2011; Caiazzo et al., 2011; Rivetti Di Val Cervo et al., 2017).

The transcription factor PAX6 is a key determinant of the neurogenic potential of glial cells from the cortex (Heins et al., 2002). In the case of transformation of glia (astrocytes) from the CNS into neurons, both in vitro and in vivo, the most common approach involves TFs, such as NEUROG2, BRN4, NEUROD1, ASCL1, DLX2, and/or SOX2 (Addis et al., 2011; Guo et al., 2014; Liu et al., 2015; Brulet et al., 2017; Table 1).

In general, SCs that support the repair of damaged nerves are too short-lived to complete this process successfully. Consequently, considerable research is now focused on genetic reprogramming designed to allow SCs to retain their ability to repair damaged axons. Adenoviral vectors were the first to be successfully utilized to transduce Schwann cells in a peripheral nerve (Shy et al., 1995) and, later, lentiviral vectors were found to be even better for this purpose (Naldini et al., 1996).

Lentiviral-mediated overexpression of the trophic factor GDNF by both the intact and lesioned rat sciatic nerve elevates the density of the present SCs, but, at the same time, the morphology of these cells becomes abnormal and myelination of axons is severely impaired (Eggers et al., 2013). Moreover, although GDNF promotes the growth of local axons, the trapping of axons in the nerve ("candy store" effect) is detrimental to regeneration (Eggers et al., 2013; Santosa et al., 2013).

By employing a lentiviral vector to induce the overexpression of the neurotrophin NGF in SCs of the rat sciatic nerve, 2 weeks after injury, elevated the number of axons expressing NF200, ChAT, and CGRP and improved axonal regeneration (Shakhbazau et al., 2012). When SCs were induced to express $\mathrm{BDNF}, \mathrm{CNTF}$, or NT3, in an attempt to repair unilateral 1$\mathrm{cm}$ defects in rat peroneal nerves, the differential effects on the morphology of peripheral nerve grafts, the number and type of regenerating axons, myelination, and locomotor function were observed, 10 weeks later (Godinho et al., 2013).
TABLE 1 | Transcription factors utilized for in vivo reprogramming of glial cells into neurons in the CNS.

\begin{tabular}{|c|c|c|c|c|}
\hline $\begin{array}{l}\text { Type of CNS } \\
\text { cells } \\
\text { reprogrammed }\end{array}$ & $\begin{array}{l}\text { Transcription } \\
\text { factors }\end{array}$ & $\begin{array}{l}\text { Other } \\
\text { factors } \\
\text { added }\end{array}$ & Cells generated & References \\
\hline Astrocytes & PAX6 & None & Neurogenic cells & $\begin{array}{l}\text { Heins et al., } \\
2002\end{array}$ \\
\hline Astrocytes & NEURO2 & FGF+EGF & $\begin{array}{l}\text { Dopaminergic/ } \\
\text { glutaminergic } \\
\text { neurons }\end{array}$ & $\begin{array}{l}\text { Grande } \\
\text { et al., } 2013\end{array}$ \\
\hline $\begin{array}{l}\text { Reactive } \\
\text { astrocytes and } \\
\text { NG2 glia }\end{array}$ & NEUROD1 & None & $\begin{array}{l}\text { Glutaminergic } \\
\text { neurons }\end{array}$ & $\begin{array}{l}\text { Guo et al., } \\
2014\end{array}$ \\
\hline NG2 glia & sox2 & None & GABAergicneurons & $\begin{array}{l}\text { Heinrich } \\
\text { et al., } 2010\end{array}$ \\
\hline Astrocytes & ASCL1 & None & $\begin{array}{l}\text { Glutamatergic and } \\
\text { GABAergic neurons }\end{array}$ & $\begin{array}{l}\text { Liu et al., } \\
2015\end{array}$ \\
\hline NG2 glia & $\begin{array}{l}\text { ASCL1 + } \\
\text { LMX1a + } \\
\text { NURR1 }\end{array}$ & None & $\begin{array}{l}\text { Glutamatergic and } \\
\text { GABAergic neurons }\end{array}$ & $\begin{array}{l}\text { Torper et al., } \\
2013\end{array}$ \\
\hline Astrocytes & $\begin{array}{l}\text { NEUROD1 + } \\
\text { ASCL1 }+ \\
\text { LMX1a }\end{array}$ & $\operatorname{miR} 218$ & $\begin{array}{l}\text { Dopaminergic } \\
\text { neurons }\end{array}$ & $\begin{array}{l}\text { Rivetti Di Val } \\
\text { Cervo et al., } \\
2017\end{array}$ \\
\hline Astrocytes & NEUROD1 & None & Neurons & $\begin{array}{l}\text { Brulet et al., } \\
2017\end{array}$ \\
\hline Astrocytes & sox2 & VPA & GABAergic neurons & $\begin{array}{l}\text { Su et al., } \\
2014\end{array}$ \\
\hline Astrocytes & sox2 & $\begin{array}{l}\text { VPA + } \\
\text { BDNF + } \\
\text { NOGGIN }\end{array}$ & $\begin{array}{l}\text { GABAergic, } \\
\text { glycinergic, } \\
\text { serotonergic, } \\
\text { cholinergic neurons }\end{array}$ & $\begin{array}{l}\text { Wang et al., } \\
2016\end{array}$ \\
\hline
\end{tabular}

In general, glial cells are readily available and apparently suitable for direct reprogramming into neurons. Since the neurons and glia in the CNS originate from the same neural population, their epigenetic profiles are, presumably, the same. It is highly likely that experimenting with many more different types of adult cells and transcription factors will increase the yields of the target cells and, at the same time, lower the cost of future therapies.

\section{Glial Reprogramming in vivo in the Context of Neurological Diseases}

At present, the progressive damage and death of neurons, which are post-mitotic and do not regenerate, is incurable. The source of the differentiated cells to be reprogrammed is important. Parenchymal astrocytes and $\mathrm{NG}^{+}$glia have been successfully reprogrammed into $\mathrm{NEUN}^{+}$dopaminergic, glutaminergic, and GABA neurons of the striatum and cortex, using lentiviral vectors. These vectors have encoded a single TF (NEUROD, SOX2, or ASCL1) (Heinrich et al., 2010; Guo et al., 2014; Liu et al., 2015) or a mixture of these factors (ASCL1 + BRN2 + MYT1 or NEUROD + ASCL1 + LMX1a + miR218 or SOX2, together with the neurotrophic factors BDNF + NOGGIN, or NEUROG2 with FGF + EGF) (Grande et al., 2013; Torper et al., 2013; Rivetti Di Val Cervo et al., 2017; Table 1). Moreover, astrocytes from the spinal cord can be transdifferentiated into GABA-, glycin-, serotonin-, and cholinergic neurons through the 
overexpression of Sox2, together with the addition of valproic acid (which inhibits histone deacetylase), BDNF, and NOGGIN (Su et al., 2014; Wang et al., 2016; Table 1).

As indicated above, despite recent progress in increasing the yield of neurons from transformed glia, relatively few neurons have been obtained and these have survived only for a short period of time. These limitations may be overcome through the addition of other growth factors (e.g., FGF2, EGF) or/and chemicals (calcitriol, $\alpha$-tocotrienol) (Grande et al., 2013; Gascón et al., 2016). In addition, appropriate alterations of the microenvironment (e.g., through co-expression of BDNF and NOG, or the presence of VPA) might also influence the maturation and survival of neurons in vivo (Niu et al., 2015; Wang et al., 2016).

In this context, reprogramming of glial cells, for example, in order to obtain new neurons during development, might also offer a viable approach to treatment in vivo (Bertrand et al., 2002; Dyachuk et al., 2014). One example of how this strategy has already been utilized successfully is in the transformation of spiral ganglion glial cells into auditory neurons to restore hearing (Noda et al., 2018). Direct conversion of glial cell into neurons of the CNS may eventually provide an effective treatment for various neurodegenerative diseases, such as ALS, Alzheimer's (AD), and Parkinson's (PD) disease. For example, in mice with PD, the treatment of astrocytes with a lentiviral vector that induced the overexpression of the transcription factors NEUROD1, ASCL1, LMX1A, and miR218, increased their numbers of dopaminergic neurons and led to the recovery of motor function, 5 weeks after treatment (Rivetti Di Val Cervo et al., 2017). In addition, in $\mathrm{AD}$ animal models, reactive glial cells can produce the transcription factor NEUROD1, which leads to the reprogramming of astrocytes into glutamatergic neurons, and of NG2 glial cells into glutamatergic and GABAergic neurons (Guo et al., 2014).

These examples of the reprogramming of glial cells into functional neurons are promising for the restoration of lost neurons, due to neurological damage or disease. In fact, in vivo reprogramming has several major advantages over in vitro approaches, including the maintenance of natural microenvironments, absence of complications associated with cell grafting, and a more efficient transdifferentiation. However, many questions remain unanswered. For example, whether transdifferentiation may be used to treat the cognitive and behavioral deficits that are becoming more common worldwide. Moreover, the problem of finding a more suitable source of cells with pronounced plasticity, rapid growth, and the ability to produce different types of neurons, still remains.

If reprogrammed cells are to be used successfully to treat neurodegenerative diseases, the neurons obtained must connect with other neurons to form functional pathways. In this context a significant achievement has been glial reprogramming into excitatory glutamatergic, inhibitory GABAergic, and dopaminergic neurons, which exhibit the electrophysiological properties of mature neurons, including action potential and synaptic connections (Grande et al., 2013; Torper et al., 2013; Guo et al., 2014; Su et al., 2014; Liu et al., 2015; Wang et al., 2016; Brulet et al., 2017; Rivetti Di Val Cervo et al., 2017).
In fact, although integration of "newborn" neurons into networks has been convincingly shown in several investigations, the full recovery of lost or damaged neuronal networks remains to be demonstrated. Clearly, much more insight into the mechanisms underlying neuronal transformation is required and single-cell deep sequencing, bioinformatics, and electrophysiological data should be of considerable value in this context.

\section{Reprogramming of SCs in the Tumor Milieu}

For a long period, SCs were considered to not be involved in carcinogenesis and research on the promotion of cancer development, both in vivo and in vitro, has focused primarily on innervation by peripheral axons (Magnon et al., 2013). However, it is now clear that a dedifferentiated SCs phenotype, strongly reminiscent of those which arise in response to nerve injury, enables cancer progression (Deborde et al., 2016). In fact, SCs promote infiltration of peripheral nerves by cancer cells (perineural invasion, PNI) by establishing an early contact with these cells, thereby attracting them to the location of SCs (Demir et al., 2014; Figure 4).

More specifically, the motility and invasiveness of cancer cells depends on the secretion of chemokines by SCs and on the expression of the corresponding receptors on tumor cells (Deborde et al., 2016; Zhou et al., 2018). Moreover, SCs can degrade the extracellular matrix to form tunnels or bands coated with laminin, along which cancer cells migrate (Deborde and Wong, 2017). In addition, the release of BDNF by SCs promotes EMT in cancer cells, together with the loss of E-cadherin and the upregulation of NCAM1, thereby facilitating migration and invasion (Azam and Pecot, 2016; Deborde et al., 2016; Shan et al., 2016). Accordingly, SCs first attract cancer cells, and later, promote their invasion into nerves (Figure 4).

Interestingly, to promote their own perineural invasion, cancer cells exploit some of the canonical functions and features of SCs (plasticity, the ability to dedifferentiate in response to injury, alterations in the ECM), otherwise involved in neuronal repair and regulation. Genes expressed by pre-myelinating SCs, such as Gfap, Ncam, L1-cam, P75, and Sox2, have been implicated in this invasion (Demir et al., 2014, 2016). Thus, cancer cells can reprogram mature myelinated SCs into iSCs, which are more flexible and mobile (Jessen and Mirsky, 2019a). Moreover, as shown by Deborde et al. (2016), Gfap is expressed at high levels by dedifferentiated SCs, being closely associated with cancer cells, but not, at all, by differentiated Schwann cells, similarly, to the involvement of SCs in the repair of nerves (Jessen and Mirsky, 2019a).

At the same time, cancer cells interact with other types of normal cells as well, including immune cells that infiltrate the tumor and modulate its invasion (Shurin, 2012). Such recruitment of immune cells, which accelerates tumorigenesis, can be aided by SCs, in an analogous manner to the recruitment of immune cells during nerve repair (Deborde and Wong, 2017; Jessen and Mirsky, 2019b). Moreover, SCs modulate the activity of the immune cells that are, thus, recruited. For 


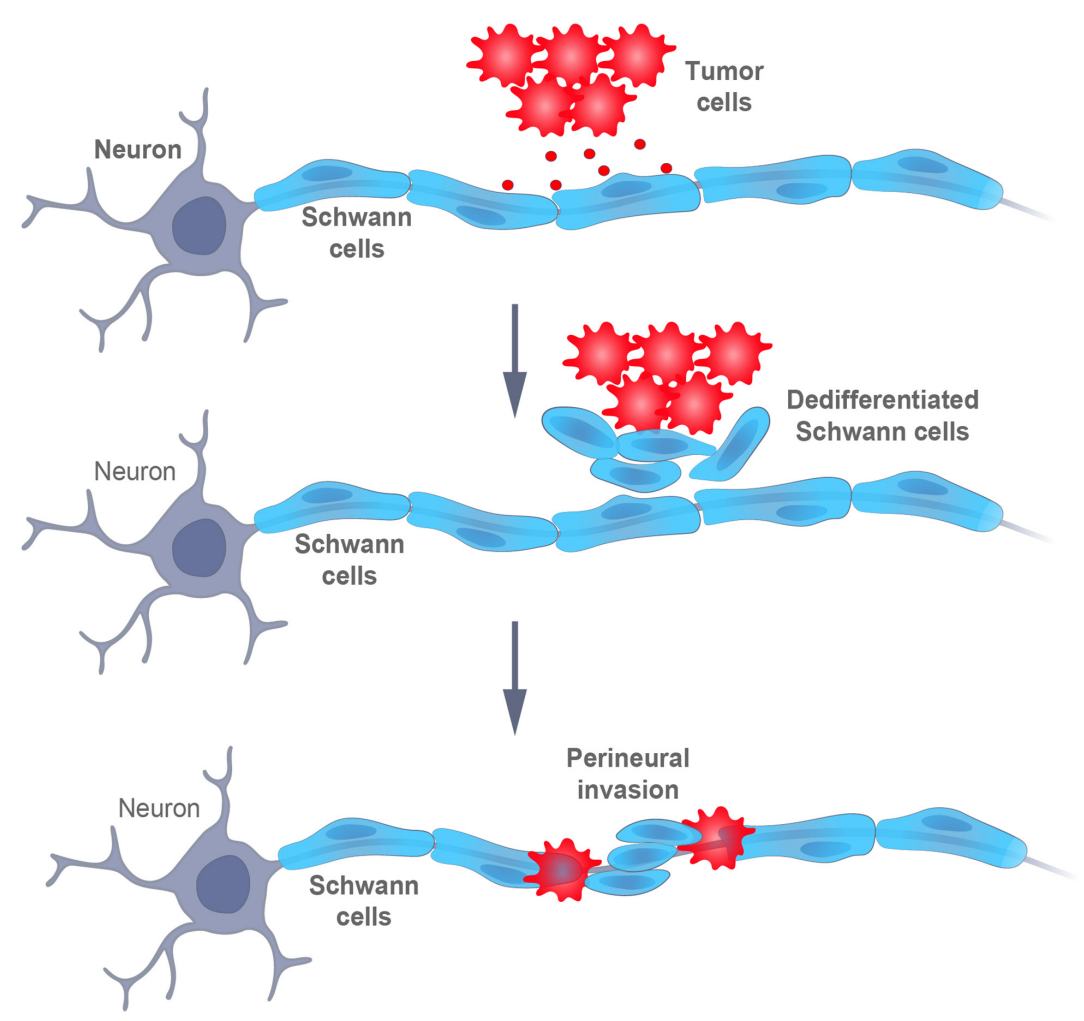

FIGURE 4 | Schematic representation of the interaction between tumor and Schwann cells. Signals from the cancer cells promote the dedifferentiation of Schwann cells, which, then, intermingle with the cancer cells and promote their dispersal and, finally, perineural invasion (i.e., infiltration within or around the nerves).

example, SCs exposed to melanoma cells in vitro enhance the ability of myeloid-derived suppressor cells (MDSCs) to suppress $\mathrm{T}$ cell proliferation (Martyn et al., 2019). In addition, the exposure of SCs to tumor cells elevates their expression of myelin-associated glycoprotein (MAG), which inhibits axonal growth and influences glia-axon interactions (Quarles, 2007). Indeed, MAG itself increases the immunosuppressive potential of MDSCs in a $\mathrm{T}$ cell inhibitory assay in a similar manner to that through which SCs are exposed to tumor cells (Martyn et al., 2019). Thus, factors released by cancer cells exert effects on SCs, which attract immune cells, that participate in the formation of the microenvironment which determines the course of tumor development.

\section{CONCLUSION}

The findings summarized here indicate that SCs can be transformed into different types of cells, both ontogenetically under natural conditions and experimentally in the laboratory. The multipotent properties of early populations of SC precursors make them attractive candidates for correcting various developmental pathologies. Furthermore, the adaptive reprogramming of SCs, in connection with axonal regeneration, gives rise to glia that can be transformed experimentally into different cell types, opens up new approaches to regenerative therapy of traumatic brain and spinal cord injuries, as well as neurodegenerative diseases.

In addition, a more detailed understanding of the molecular mechanisms underlying the promotion of carcinogenesis by SCs, primarily by facilitating perineural invasion and dissemination, may allow the treatment designed to suppress the initial stages of cancer development. Such an approach could also provide an alternative to anti-cancer therapies that target nerve fibers, which are usually quite toxic. Finally, our evolving understanding of the role played by SCs in carcinogenesis may promote the development of efficient approaches to managing cancer pain syndrome.

\section{AUTHOR CONTRIBUTIONS}

VM and VD were responsible for the intellectual content of this work. VD wrote the manuscript. Both authors contributed to the article and approved the submitted version.

\section{FUNDING}

This study was financially supported by the Russian Science Foundation (Grant 18-75-10005), RFBR (Grant 19-29-04035), and the Government of the Russian Federation through an ITMO Fellowship and the Professorship Program. 


\section{REFERENCES}

Abdo, H., Calvo-Enrique, L., Lopez, J. M., Song, J., Zhang, M. D., Usoskin, D., et al. (2019). Specialized cutaneous schwann cells initiate pain sensation. Science 365, 695-699. doi: 10.1126/science.aax6452

Adameyko, I., Lallemend, F., Aquino, J. B., Pereira, J. A., Topilko, P., Müller, T., et al. (2009). Schwann cell precursors from nerve innervation are a cellular origin of melanocytes in skin. Cell 139, 366-379. doi: 10.1016/j.cell.2009.07.049

Addis, R. C., Hsu, F. C., Wright, R. L., Dichter, M. A., Coulter, D. A., and Gearhart, J. D. (2011). Efficient conversion of astrocytes to functional midbrain dopaminergic neurons using a single polycistronic vector. PLoS One 6:e28719. doi: 10.1371/journal.pone.0028719

Adler, A. F., Grigsby, C. L., Kulangara, K., Wang, H., Yasuda, R., and Leong, K. W. (2012). Nonviral direct conversion of primary mouse embryonic fibroblasts to neuronal cells. Mol. Ther. Nucleic Acids. 1:e32. doi: 10.1038/mtna.2012.25

Alvarez-Suarez, P., Gawor, M., and Prószyński, T. J. (2020). Perisynaptic schwann cells - the multitasking cells at the developing neuromuscular junctions. Semin. Cell Dev. Biol. 104, 31-38. doi: 10.1016/j.semcdb.2020.02.011

Arthur-Farraj, P. J., Latouche, M., Wilton, D. K., Quintes, S., Chabrol, E., Banerjee, A., et al. (2012). c-Jun reprograms schwann cells of injured nerves to generate a repair cell essential for regeneration. Neuron 75, 633-647. doi: 10.1016/j. neuron.2012.06.021

Arthur-Farraj, P. J., Morgan, C. C., Adamowicz, M., Gomez-Sanchez, J. A., Fazal, S. V., Beucher, A., et al. (2017). Changes in the coding and noncoding transcriptome and DNA methylome that define the schwann cell repair phenotype after nerve injury. Cell Rep. 20, 2719-2734. doi: 10.1016/j.celrep. 2017.08.064

Azam, S. H., and Pecot, C. V. (2016). Cancer's got nerve: schwann cells drive perineural invasion. J. Clin. Invest. 126, 1242-1244. doi: 10.1172/JCI86801

Barres, B. A. (2008). The mystery and magic of glia: a perspective on their roles in health and disease. Neuron 60, 430-440. doi: 10.1016/j.neuron.2008. 10.013

Bertrand, N., Castro, D. S., and Guillemot, F. (2002). Proneural genes and the specification of neural cell types. Nat. Rev. Neurosci. 3, 517-530. doi: 10.1038/ nrn874

Biernaskie, J., Paris, M., Morozova, O., Fagan, B. M., Marra, M., Pevny, L., et al. (2009). SKPs derive from hair follicle precursors and exhibit properties of adult dermal stem cells. Cell Stem Cell 5, 610-623. doi: 10.1016/j.stem.2009.10.019

Birchmeier, C. (2009). ErbB receptors and the development of the nervous system. Exp. Cell Res. 315, 611-618. doi: 10.1016/j.yexcr.2008.10.035

Birchmeier, C., and Nave, K.-A. (2008). Neuregulin-1, a key axonal signal that drives Schwann cell growth and differentiation. Glia 56, 1491-1497. doi: 10. 1002/glia.20753

Britsch, S., Goerich, D. E., Riethmacher, D., Peirano, R. I., Rossner, M., Nave, K. A., et al. (2001). The transcription factor Sox10 is a key regulator of peripheral glial development. Genes Dev. 15, 66-78. doi: 10.1101/gad.186601

Britsch, S., Li, L., Kirchhoff, S., Theuring, F., Brinkmann, V., Birchmeier, C., et al. (1998). The ErbB2 and ErbB3 receptors and their ligand, neuregulin-1, are essential for development of the sympathetic nervous system. Genes Dev. 12, 1825-1836. doi: 10.1101/gad.12.12.1825

BrosiusLutz, A., and Barres, B. A. (2014). Contrasting the glial response to axon injury in the central and peripheral nervous systems. Dev. Cell 28, 7-17. doi: 10.1016/j.devcel.2013.12.002

Brulet, R., Matsuda, T., Zhang, L., Miranda, C., Giacca, M., Kaspar, B. K., et al. (2017). NEUROD1 instructs neuronal conversion in non-reactive astrocytes. Stem Cell Rep. 8, 1506-1515. doi: 10.1016/j.stemcr.2017.04.013

Byers, M. R. (1985). Sensory innervation of periodontal ligament of rat molars consists of unencapsulated Ruffini-like mechanoreceptors and free nerve endings. J. Comp. Neurol. 231, 500-518. doi: 10.1002/cne.902310408

Caiazzo, M., Dell'Anno, M. T., Dvoretskova, E., Lazarevic, D., Taverna, S., Leo, D., et al. (2011). Direct generation of functional dopaminergic neurons from mouse and human fibroblasts. Nature 476, 224-227. doi: 10.1038/nature10284

Chen, Y., Wang, H., Yoon, S. O., Xu, X., Hottiger, M. O., Svaren, J., et al. (2011). HDAC-mediated deacetylation of NF- $\kappa \mathrm{B}$ is critical for Schwann cell myelination. Nat. Neurosci. 14, 437-441. doi: 10.1038/nn.2780

Cheng, L., Hu, W., Qiu, B., Zhao, J., Yu, Y., Guan, W., et al. (2014). Generation of neural progenitor cells by chemical cocktails and hypoxia. Cell Res. 24, 665-679. doi: $10.1038 / \mathrm{cr} .2014 .32$
Clements, M. P., Byrne, E., Camarillo Guerrero, L. F., Cattin, A. L., Zakka, L., Ashraf, A., et al. (2017). The wound microenvironment reprograms schwann cells to invasive mesenchymal-like cells to drive peripheral nerve regeneration. Neuron 96, 98-114.e7. doi: 10.1016/j.neuron.2017.09.008

Deborde, S., Omelchenko, T., Lyubchik, A., Zhou, Y., He, S., McNamara, W. F., et al. (2016). Schwann cells induce cancer cell dispersion and invasion. J. Clin. Invest. 126, 1538-1554. doi: 10.1172/JCI82658

Deborde, S., and Wong, R. J. (2017). How Schwann cells facilitate cancer progression in nerves. Cell. Mol. Life Sci. 74, 4405-4420. doi: 10.1007/s00018017-2578-x

Demir, I. E., Boldis, A., Pfitzinger, P. L., Teller, S., Brunner, E., Klose, N., et al. (2014). Investigation of schwann cells at neoplastic cell sites before the onset of cancer invasion. J. Natl. Cancer Inst. 106:dju184. doi: 10.1093/jnci/ dju184

Demir, I. E., Tieftrunk, E., Schorn, S., Saricaoglu, ÖC., Pfitzinger, P. L., Teller, S., et al. (2016). Activated Schwann cells in pancreatic cancer are linked to analgesia via suppression of spinal astroglia and microglia. Gut 65, 1001-1014. doi: 10.1136/gutjnl-2015-309784

Dooley, C. M., Mongera, A., Walderich, B., and Nusslein-Volhard, C. (2013). On the embryonic origin of adult melanophores: the role of ErbB and Kit signalling in establishing melanophore stem cells in zebrafish. Development 140 , 1003-1013. doi: 10.1242/dev.087007

Dyachuk, V., Furlan, A., Shahidi, M. K., Giovenco, M., Kaukua, N., Konstantinidou, C., et al. (2014). Parasympathetic neurons originate from nerve-associated peripheral glial progenitors. Science 345, 82-87. doi: $10.1126 /$ science. 1253281

Eggers, R., de Winter, F., Hoyng, S. A., Roet, K. C. D., Ehlert, E. M., Malessy, M. J. A., et al. (2013). Lentiviral vector-mediated gradients of GDNF in the injured peripheral nerve: effects on nerve coil formation, schwann cell maturation and myelination. PLoS One. 8:e71076. doi: 10.1371/journal.pone. 0071076

Espinosa-Medina, I., Jevans, B., Boismoreau, F., Chettouh, Z., Enomoto, H., Müller, T., et al. (2017). Dual origin of enteric neurons in vagal Schwann cell precursors and the sympathetic neural crest. Proc. Natl. Acad. Sci. U.S.A. 114, 11980-11985. doi: 10.1073/pnas.1710308114

Furlan, A., Dyachuk, V., Kastriti, M. E., Calvo-Enrique, L., Abdo, H., Hadjab, S., et al. (2017). Multipotent peripheral glial cells generate neuroendocrine cells of the adrenal medulla. Science 357:eaal3753. doi: 10.1126/science.aal3753

Garratt, A. N., Britsch, S., and Birchmeier, C. (2000). Neuregulin, a factor with many functions in the life of a Schwann cell. BioEssays 22, 987-996. doi: 10.1002/1521-1878(200011)22:11<987::aid-bies5>3.0.co;2-5

Gascón, S., Murenu, E., Masserdotti, G., Ortega, F., Russo, G. L., Petrik, D., et al. (2016). Identification and successful negotiation of a metabolic checkpoint in direct neuronal reprogramming. Cell Stem Cell 18, 396-409. doi: 10.1016/j.stem. 2015.12.003

Godinho, M. J., Teh, L., Pollett, M. A., Goodman, D., Hodgetts, S. I., Sweetman, I., et al. (2013). Immunohistochemical, ultrastructural and functional analysis of axonal regeneration through peripheral nerve grafts containing schwann cells expressing BDNF, CNTF or NT3. PLoS One 8:e69987. doi: 10.1371/journal. pone.0069987

Gonçalves, N. P., Vægter, C. B., and Pallesen, L. T. (2018). Peripheral glial cells in the development of diabetic neuropathy. Front. Neurol. 9:268. doi: 10.3389/ fneur.2018.00268

Grande, A., Sumiyoshi, K., López-Juárez, A., Howard, J., Sakthivel, B., Aronow, B., et al. (2013). Environmental impact on direct neuronal reprogramming in vivo in the adult brain. Nat. Commun. 4:2373. doi: 10.1038/ncomms3373

Grath, A., and Dai, G. (2019). Direct cell reprogramming for tissue engineering and regenerative medicine. J. Biol. Eng. 13:14. doi: 10.1186/s13036-019-0144-9

Gresset, A., Coulpier, F., Gerschenfeld, G., Jourdon, A., Matesic, G., Richard, L., et al. (2015). Boundary caps give rise to neurogenic stem cells and terminal glia in the skin. Stem Cell Rep. 5, 278-290. doi: 10.1016/j.stemcr.2015. 06.005

Guo, Z., Zhang, L., Wu, Z., Chen, Y., Wang, F., and Chen, G. (2014). In vivo direct reprogramming of reactive glial cells into functional neurons after brain injury and in an Alzheimer's disease model. Cell Stem Cell 14, 188-202. doi: 10.1016/j.stem.2013.12.001

Heinrich, C., Blum, R., Gascón, S., Masserdotti, G., Tripathi, P., Sánchez, R., et al. (2010). Directing astroglia from the cerebral cortex into subtype 
specific functional neurons. PLoS Biol. 8:e1000373. doi: 10.1371/journal.pbio. 1000373

Heins, N., Malatesta, P., Cecconi, F., Nakafuku, M., Tucker, K. L., Hack, M. A., et al. (2002). Glial cells generate neurons: the role of the transcription factor Pax6. Nat. Neurosci. 5, 308-315. doi: 10.1038/nn828

Honjo, Y., Kniss, J., and Eisen, J. S. (2008). Neuregulin-mediated ErbB3 signaling is required for formation of zebrafish dorsal root ganglion neurons. Development 135, 2615-2625. doi: 10.1242/dev.022178

Hu, W., Qiu, B., Guan, W., Wang, Q., Wang, M., Li, W., et al. (2015). Direct conversion of normal and Alzheimer's disease human fibroblasts into neuronal cells by small molecules. Cell Stem Cell 17, 204-212. doi: 10.1016/j.stem.2015. 07.006

Hunt, D. P. J., Morris, P. N., Sterling, J., Anderson, J. A., Joannides, A., Jahoda, C., et al. (2008). A highly enriched niche of precursor cells with neuronal and glial potential within the hair follicle dermal papilla of adult skin. Stem Cells 26, 163-172. doi: 10.1634/stemcells.2007-0281

Jessen, K. R., and Mirsky, R. (2005). The origin and development of glial cells in peripheral nerves. Nat. Rev. Neurosci. 6, 671-682. doi: 10.1038/nrn1746

Jessen, K. R., and Mirsky, R. (2010). Control of schwann cell myelination. F1000 Biol. Rep. 2:19. doi: 10.3410/B2-19

Jessen, K. R., and Mirsky, R. (2016). The repair Schwann cell and its function in regenerating nerves. J. Physiol. 594, 3521-3531. doi: 10.1113/JP270874

Jessen, K. R., and Mirsky, R. (2019a). Schwann cell precursors; multipotent glial cells in embryonic nerves. Front. Mol. Neurosci. 12:69. doi: 10.3389/fnmol.2019. 00069

Jessen, K. R., and Mirsky, R. (2019b). The success and failure of the schwann cell response to nerve injury. Front. Cell. Neurosci. 13:33. doi: 10.3389/fncel.2019. 00033

Jessen, K. R., Mirsky, R., and Lloyd, A. C. (2015). Schwann cells: development and role in nerve repair. Cold Spring Harb. Perspect. Biol. 7:a020487. doi: 10.1101/ cshperspect.a020487

Johnston, A. P. W., Naska, S., Jones, K., Jinno, H., Kaplan, D. R., and Miller, F. D. (2013). Sox2-mediated regulation of adult neural crest precursors and skin repair. Stem Cell Rep. 1, 38-45. doi: 10.1016/j.stemcr.2013.04.004

Johnston, A. P. W., Yuzwa, S. A., Carr, M. J., Mahmud, N., Storer, M. A., Krause, M. P., et al. (2016). Dedifferentiated schwann cell precursors secreting paracrine factors are required for regeneration of the mammalian digit tip. Cell Stem Cell 19, 433-448. doi: 10.1016/j.stem.2016.06.002

Joseph, N. M. (2004). Neural crest stem cells undergo multilineage differentiation in developing peripheral nerves to generate endoneurial fibroblasts in addition to Schwann cells. Development 131, 5599-5612. doi: 10.1242/dev. 01429

Kastriti, M. E., and Adameyko, I. (2017). Specification, plasticity and evolutionary origin of peripheral glial cells. Curr. Opin. Neurobiol. 47, 196-202. doi: 10.1016/ j.conb.2017.11.004

Kastriti, M. E., Kameneva, P., Kamenev, D., Dyachuk, V., Furlan, A., Hampl, M., et al. (2019). Schwann cell precursors generate the majority of chromaffin cells in zuckerkandl organ and some sympathetic neurons in paraganglia. Front. Mol. Neurosci. 12:6. doi: 10.3389/fnmol.2019.00006

Kaukua, N., Shahidi, M. K., Konstantinidou, C., Dyachuk, V., Kaucka, M., Furlan, A., et al. (2014). Glial origin of mesenchymal stem cells in a tooth model system. Nature 513, 551-554. doi: 10.1038/nature13536

Kaur, K., Yang, J., Eisenberg, C. A., and Eisenberg, L. M. (2014). 5-Azacytidine promotes the transdifferentiation of cardiac cells to skeletal myocytes. Cell. Reprogram. 16, 324-330. doi: 10.1089/cell.2014.0021

Le, N., Nagarajan, R., Wang, J. Y. T., Araki, T., Schmidt, R. E., and Milbrandt, J. (2005). Analysis of congenital hypomyelinating Egr2Lo/Lo nerves identifies Sox 2 as an inhibitor of Schwann cell differentiation and myelination. Proc. Natl. Acad. Sci. U.S.A. 102, 2596-2601. doi: 10.1073/pnas.0407836102

Le Douarin, N., and Kalcheim, C. (1999). The Neural Crest. Cambridge: Cambridge University Press.

Li, K., Zhu, S., Russ, H. A., Xu, S., Xu, T., Zhang, Y., et al. (2014). Small molecules facilitate the reprogramming of mouse fibroblasts into pancreatic lineages. Cell Stem Cell 14, 228-236. doi: 10.1016/j.stem.2014.01.006

Lin, H.-P., Oksuz, I., Hurley, E., Wrabetz, L., and Awatramani, R. (2015). Microprocessor complex subunit DiGeorge syndrome critical region gene 8 (Dgcr8) is required for schwann cell myelination and myelin maintenance. J. Biol. Chem. 290, 24294-24307. doi: 10.1074/jbc.M115.636407
Liu, Y., Miao, Q., Yuan, J., Han, S., Zhang, P., Li, S., et al. (2015). Ascl1 converts dorsal midbrain astrocytes into functional neurons In Vivo. J. Neurosci. 35, 9336-9355. doi: 10.1523/JNEUROSCI.3975-14.2015

Ma, K. H., Hung, H. A., and Svaren, J. (2016). Epigenomic regulation of schwann cell reprogramming in peripheral nerve injury. J. Neurosci. 36, 9135-9147. doi: 10.1523/JNEUROSCI.1370-16.2016

Maeda, T., Ochi, K., Nakakura-Ohshima, K., Youn, S. H., and Wakisaka, S. (1999). The ruffini ending as the primary mechanoreceptor in the periodontal ligament: its morphology, cytochemical features, regeneration, and development. Crit. Rev. Oral Biol. Med. 10, 307-327. doi: 10.1177/10454411990100030401

Magnon, C., Hall, S. J., Lin, J., Xue, X., Gerber, L., Freedland, S. J., et al. (2013). Autonomic nerve development contributes to prostate cancer progression. Science 341:1236361. doi: 10.1126/science.1236361

Martyn, G. V., Shurin, G. V., Keskinov, A. A., Bunimovich, Y. L., and Shurin, M. R. (2019). Schwann cells shape the neuro-immune environs and control cancer progression. Cancer Immunol. Immunother. 68, 1819-1829. doi: 10. 1007/s00262-018-02296-3

Merrell, A. J., and Stanger, B. Z. (2016). Adult cell plasticity in vivo: dedifferentiation and transdifferentiation are back in style. Nat. Rev. Mol. Cell Biol. 17, 413-425. doi: 10.1038/nrm.2016.24

Morton, P. D., Dellarole, A., Theus, M. H., Walters, W. M., Berge, S. S., and Bethea, J. R. (2013). Activation of NF-кB in Schwann cells is dispensable for myelination In vivo. J. Neurosci. 33, 9932-9936. doi: 10.1523/JNEUROSCI.2483-12.2013

Naeem, N., Haneef, K., Kabir, N., Iqbal, H., Jamall, S., and Salim, A. (2013). DNA methylation inhibitors, 5-azacytidine and zebularine potentiate the transdifferentiation of rat bone marrow mesenchymal stem cells into cardiomyocytes. Cardiovasc. Ther. 31, 201-209. doi: 10.1111/j.1755-5922.2012. 00320.x

Naldini, L., Blomer, U., Gallay, P., Ory, D., Mulligan, R., Gage, F. H., et al. (1996). In vivo gene delivery and stable transduction of nondividing cells by a lentiviral vector. Science 272, 263-267. doi: 10.1126/science.272.5259.263

Napoli, I., Noon, L. A., Ribeiro, S., Kerai, A. P., Parrinello, S., Rosenberg, L. H., et al. (2012). A central role for the ERK-signaling pathway in controlling schwann cell plasticity and peripheral nerve regeneration in vivo. Neuron $73,729-742$. doi: 10.1016/j.neuron.2011.11.031

Nickols, J. C., Valentine, W., Kanwal, S., and Carter, B. D. (2003). Activation of the transcription factor NF- $\kappa$ B in Schwann cells is required for peripheral myelin formation. Nat. Neurosci. 6, 161-167. doi: 10.1038/nn995

Niu, W., Zang, T., Smith, D. K., Vue, T. Y., Zou, Y., Bachoo, R., et al. (2015). SOX2 reprograms resident astrocytes into neural progenitors in the adult brain. Stem Cell Rep. 4, 780-794. doi: 10.1016/j.stemcr.2015.03.006

Noda, T., Meas, S. J., Nogami, J., Amemiya, Y., Uchi, R., Ohkawa, Y., et al. (2018). Direct reprogramming of spiral ganglion non-neuronal cells into neurons: toward ameliorating sensorineural hearing loss by gene therapy. Front. Cell Dev. Biology. 6:16. doi: 10.3389/fcell.2018.00016

Ochoa-Cortes, F., Turco, F., Linan-Rico, A., Soghomonyan, S., Whitaker, E., Wehner, S., et al. (2016). Enteric Glial Cells. Inflamm. Bowel Dis. 22, 433-449. doi: 10.1097/MIB.0000000000000667

Parfejevs, V., Debbache, J., Shakhova, O., Schaefer, S. M., Glausch, M., Wegner, M., et al. (2018). Injury-activated glial cells promote wound healing of the adult skin in mice. Nat. Commun. 9:236. doi: 10.1038/s41467-01701488-2

Patel, M., and Yang, S. (2010). Advances in reprogramming somatic cells to induced pluripotent stem cells. Stem Cell Rev. Rep. 6, 367-380. doi: 10.1007/s12015-0109123-8

Pires, B. R. B., Mencalha, A. L., Ferreira, G. M., de Souza, W. F., Morgado-Díaz, J. A., Maia, A. M., et al. (2017). NF-kappaB is involved in the regulation of EMT genes in breast cancer cells. PLoS One 12:e0169622. doi: 10.1371/journal.pone. 0169622

Quarles, R. H. (2007). Myelin-associated glycoprotein (MAG): past, present and beyond. J. Neurochem. 100, 1431-1448. doi: 10.1111/j.1471-4159.2006.04319.x

Ramachandran, R., Fausett, B. V., and Goldman, D. (2010). Asclla regulates Müller glia dedifferentiation and retinal regeneration through a Lin-28-dependent, let-7 microRNA signalling pathway. Nature Cell Biology. 12, 1101-1107. doi: $10.1038 /$ ncb2115

Raymond, P. A., Barthel, L. K., Bernardos, R. L., and Perkowski, J. J. (2006). Molecular characterization of retinal stem cells and their niches in adult zebrafish. BMC Dev. Biol. 6:36. doi: 10.1186/1471-213X-6-36 
Riethmacher, D., Sonnenberg-Riethmacher, E., Brinkmann, V., Yamaai, T., Lewin, G. R., and Birchmeier, C. (1997). Severe neuropathies in mice with targeted mutations in the ErbB3 receptor. Nature 389, 725-730. doi: 10.1038/39593

Rivetti Di Val Cervo, P., Romanov, R. A., Spigolon, G., Masini, D., MartínMontañez, E., Toledo, E. M., et al. (2017). Induction of functional dopamine neurons from human astrocytes in vitro and mouse astrocytes in a Parkinson's disease model. Nat. Biotechnol. 35, 444-452. doi: 10.1038/nbt.3835

Rubio, A., Luoni, M., Giannelli, S. G., Radice, I., Iannielli, A., Cancellieri, C., et al. (2016). Rapid and efficient CRISPR/Cas9 gene inactivation in human neurons during human pluripotent stem cell differentiation and direct reprogramming. Sci. Rep. 6:37540. doi: 10.1038/srep37540

Santosa, K. B., Jesuraj, N. J., Viader, A., Macewan, M., Newton, P., Hunter, D. A., et al. (2013). Nerve allografts supplemented with schwann cells overexpressing glial-cell-line-derived neurotrophic factor. Muscle Nerve 47, 213-223. doi: 10. 1002/mus.23490

Sayed, N., Wong, W. T., Ospino, F., Meng, S., Lee, J., Jha, A., et al. (2015). Transdifferentiation of human fibroblasts to endothelial cells role of innate immunity. Circulation 131, 300-309. doi: 10.1161/CIRCULATIONAHA.113. 007394

Shakhbazau, A., Kawasoe, J., Hoyng, S. A., Kumar, R., van Minnen, J., Verhaagen, J., et al. (2012). Early regenerative effects of NGF-transduced Schwann cells in peripheral nerve repair. Mol. Cell. Neurosci. 50, 103-112. doi: 10.1016/j.mcn. 2012.04.004

Shan, C., Wei, J., Hou, R., Wu, B., Yang, Z., Wang, L., et al. (2016). Schwann cells promote EMT and the Schwann-like differentiation of salivary adenoid cystic carcinoma cells via the BDNF/TrkB Axis. Oncol. Rep. 35, 427-435. doi: 10.3892/or.2015.4366

Shurin, M. (2012). Cancer as an immune-mediated disease. ImmunoTargets Ther. 1, 1-6. doi: 10.2147/ITT.S29834

Shy, M. E., Tani, M., Shi, Y. -J., Whyatt, S. A., Chbihi, T., Scherer, S. S., et al. (1995). An adenoviral vector can transfer lacZ expression into schwann cells in culture and in sciatic nerve. Ann. Neurol. 38, 429-436. doi: 10.1002/ana.410380313

Soldatov, R., Kaucka, M., Kastriti, M. E., Petersen, J., Chontorotzea, T., Englmaier, L., et al. (2019). Spatiotemporal structure of cell fate decisions in murine neural crest. Science 364:eaas9536. doi: 10.1126/science.aas9536

$\mathrm{Su}, \mathrm{Z}$., and He, C. (2010). Olfactory ensheathing cells: biology in neural development and regeneration. Prog. Neurobiol. 92, 517-532. doi: 10.1016/j. pneurobio.2010.08.008

Su, Z., Niu, W., Liu, M. L., Zou, Y., and Zhang, C. L. (2014). In vivo conversion of astrocytes to neurons in the injured adult spinal cord. Nat. Commun. 5:3338. doi: $10.1038 /$ ncomms 4338

Takahashi, K., and Yamanaka, S. (2006). Induction of pluripotent stem cells from mouse embryonic and adult fibroblast cultures by defined factors. Cell 126, 663-676. doi: 10.1016/j.cell.2006. 07.024

Taranova, O. V., Magness, S. T., Fagan, B. M., Wu, Y., Surzenko, N., Hutton, S. R., et al. (2006). SOX2 is a dose-dependent regulator of retinal neural progenitor competence. Genes Dev. 20, 1187-1202. doi: 10.1101/gad.14 07906

Torper, O., Pfisterer, U., Wolf, D. A., Pereira, M., Lau, S., Jakobsson, J., et al. (2013). Generation of induced neurons via direct conversion in vivo. Proc. Natl. Acad. Sci. U.S.A. 110, 7038-7043. doi: 10.1073/pnas.1303829110

Vierbuchen, T., Ostermeier, A., Pang, Z. P., Kokubu, Y., Südhof, T. C., and Wernig, M. (2010). Direct conversion of fibroblasts to functional neurons by defined factors. Nature 8:207. doi: 10.1038/nature08797

Wang, L.-L., Su, Z., Tai, W., Zou, Y., Xu, X.-M., and Zhang, C.-L. (2016). The p53 pathway controls SOX2-mediated reprogramming in the adult mouse spinal cord. Cell Rep. 17, 891-903. doi: 10.1016/j.celrep.2016.09.038

Wolpowitz, D., Mason, T. B. A., Dietrich, P., Mendelsohn, M., Talmage, D. A., and Role, L. W. (2000). Cysteine-rich domain isoforms of the neuregulin-1 gene are required for maintenance of peripheral synapses. Neuron 25, 79-91. doi: 10.1016/S0896-6273(00)80873-9

Woodhoo, A., Alonso, M. B. D., Droggiti, A., Turmaine, M., D’Antonio, M., Parkinson, D. B., et al. (2009). Notch controls embryonic Schwann cell differentiation, postnatal myelination and adult plasticity. Nat. Neurosci. 12, 839-847. doi: 10.1038/nn.2323

Xie, M., Kamenev, D., Kaucka, M., Kastriti, M. E., Zhou, B., Artemov, A. V., et al. (2019). Schwann cell precursors contribute to skeletal formation during embryonic development in mice and zebrafish. Proc. Natl. Acad. Sci. U.S.A. 116, 15068-15073. doi: 10.1073/pnas.1900038116

Yoo, A. S., Sun, A. X., Li, L., Shcheglovitov, A., Portmann, T., Li, Y., et al. (2011). MicroRNA-mediated conversion of human fibroblasts to neurons. Nature 476, 228-231. doi: 10.1038/nature10323

Zhou, Y., Shurin, G. V., Zhong, H., Bunimovich, Y. L., Han, B., and Shurin, M. R. (2018). Schwann cells augment cell spreading and metastasis of lung cancer. Cancer Res. 78, 5927-5939. doi: 10.1158/0008-5472.CAN-181702

Zujovic, V., Thibaud, J., Bachelin, C., Vidal, M., Deboux, C., Coulpier, F., et al. (2011). Boundary cap cells are peripheral nervous system stem cells that can be redirected into central nervous system lineages. Proc. Natl. Acad. Sci. U.S.A. 108, 10714-10719. doi: 10.1073/pnas.1018687108

Conflict of Interest: The authors declare that the research was conducted in the absence of any commercial or financial relationships that could be construed as a potential conflict of interest.

The handling editor declared a past co-authorship with one of the authors VD.

Copyright (c) 2020 Milichko and Dyachuk. This is an open-access article distributed under the terms of the Creative Commons Attribution License (CC BY). The use, distribution or reproduction in other forums is permitted, provided the original author(s) and the copyright owner(s) are credited and that the original publication in this journal is cited, in accordance with accepted academic practice. No use, distribution or reproduction is permitted which does not comply with these terms. 